\title{
Single-center Study Comparing Short and Mid- Term Results of EVAR in Old and Young Populations
}

\author{
Mihriban Yalcin ${ }^{1}$, MD; Osman Tiryakioglu², MD
}

DOI: $10.21470 / 1678-9741-2018-0021$

\begin{abstract}
Objective: The purpose of this study was to compare the operative mortality rate and outcomes of endovascular aneurysm repair (EVAR) between young and geriatric people in a single center.

Methods: Eighty-five patients with abdominal aortic aneurysms who underwent EVAR between January 2012 and September 2016 were included. Outcomes were compared between two groups: the young (aged $<65$ years) and the geriatric (aged $\geq 65$ years). The primary study outcome was technical success; the secondary endpoints were mortality and secondary interventions. The mean follow-up time was 36 months (3-60 months).

Results: The study included 72 males and 13 females with a mean age of 71.08 \pm 8.6 years (range $49-85$ years). Of the 85 patients analyzed, $18(21.2 \%)$ were under 65 years old and 67
\end{abstract}

patients $(\mathbf{7 8 . 8} \%)$ were over 65 years old. There was no statistically significant correlation between chronic disease and age. We found no statistically significant difference between aneurysm diameter, neck angle, neck length, or right and left iliac angles. The secondary intervention rate was $7 \%$ (six patients). The conversion to open surgery was necessary for only one patient and only three deaths were reported (3.5\%). There was no statistically significant difference in the mortality and reintervention rates between the age groups. The three deaths occurred only in the geriatric group and two died secondary to rupture. Kidney failure was observed in three patients in the geriatric group (4.5\%).

Conclusion: Our single-center experience shows that EVAR can be used safely in both young and geriatric patients.

Keywords: Abdominal Aortic Aneurysm. Endovascular Aneurysm Repair. Geriatry.

\section{Abbreviations, acronyms \& symbols}

$\begin{array}{ll}\text { AAAs } & =\text { Abdominal aortic aneurysms } \\ \text { CAD } & =\text { Coronary artery disease } \\ \text { CKD } & =\text { Chronic kidney disease } \\ \text { COPD } & =\text { Chronic obstructive pulmonary disease } \\ \text { CT } & =\text { Computed tomography } \\ \text { DM } & =\text { Diabetes mellitus } \\ \text { EVAR } & =\text { Endovascular aneurysm repair } \\ \text { ICU } & =\text { Intensive care unit } \\ \text { OSR } & =\text { Open surgery repair } \\ \text { PAD } & =\text { Peripheral arterial disease } \\ \text { SD } & =\text { Standard deviation }\end{array}$

\section{INTRODUCTION}

Although aneurysms can occur anywhere in the arterial system, approximately $80 \%$ of them occur in the abdominal aorta. Therefore, endovascular aortic repair is most commonly performed to treat infrarenal abdominal aortic aneurysms (AAAs) ${ }^{[1]}$.

'Department of Cardiovascular Surgery, Ordu State Hospital, Ordu, Turkey. ${ }^{2}$ Department of Cardiovascular Surgery, Medical Faculty, Bahcesehir University, Bursa, Turkey.

This study was carried out at the Ordu Devlet Hastanesi, Sahincili, Ordu, Turkey.
AAA is associated with rupture and is managed via either open surgery repair (OSR) or endovascular aneurysm repair (EVAR). EVAR has become the first-choice treatment for anatomically-suitable $A A A s^{[2]}$.

Advanced age, male sex, and clinical comorbidities, such as cardiac, renal, or pulmonary impairment, are associated with survival after AAA repair ${ }^{[3]}$.

The aim of this study is to share the rates of complications, secondary interventions, survival, and mortality after EVAR and to compare the outcomes of young and geriatric groups after EVAR in a single-center, retrospective study.

\section{METHODS}

Patients that underwent primary EVAR for infrarenal AAA at a single institution were evaluated retrospectively.

This study included 85 patients that were treated between January 2012 and September 2016; 78 patients electively underwent EVAR and seven underwent EVAR as urgent treatment. In total, 72 patients (84.7\%) were male and 13 (15.3\%) were female (mean age was $71 \pm 8.6$ years). Patients were followed up for 36 months (3-60 months).

Correspondence Address:

Mihriban Yalçın

(iD) https://orcid.org/0000-0003-4767-0880

Ordu Devlet Hastanesi

Sahincili Mah, Devlet Hastanesi, Ordu, Turkey

Zip Code: 52200

E-mail: mihribandemir33@hotmail.com

Article received on January $24^{\text {th }}, 2018$. Article accepted on July $21^{\text {st }}, 2018$. 
The patients were divided into two groups according to their age: young (aged $<65$ years) and geriatric (aged $\geq 65$ years). An informed consent form about the endovascular treatment was obtained from all patients. The study was retrospective and did not require the approval of the local ethics committee. Table 1 shows the characteristics of the AAA patients that were included in this study. Figure 1 shows the descriptive properties of people in this study. And Table 2 shows the patients' averages in terms of age, aneurysm diameter, neck angle, neck length, right iliac angle, and left iliac angle.

The mean aneurysm diameter was $71.59 \pm 12.55 \mathrm{~cm}$ and the average neck angle was $64.39^{\circ} \pm 18.44^{\circ}$. The mean neck length was $14.12 \pm 6.13 \mathrm{~cm}$. The mean right external iliac diameter was $7.9 \pm 3.1 \mathrm{~mm}(5-9 \mathrm{~mm})$ and the mean left external iliac diameter was $7.4 \pm 2.8 \mathrm{~mm}(4.5-8 \mathrm{~mm})$ in the treated patients.

The indication for EVAR was based on the patients'comorbidities, aneurysm configuration, and patient's and surgeon's preferences. EVAR is indicated for infrarenal fusiform AAA with diameter $\geq 5 \mathrm{~cm}$, AAA associated with iliac aneurysms with diameter $\geq 3 \mathrm{~cm}$, saccular aneurysms, false aneurysms, and aneurysms with rupture.

EVAR was performed under general anesthesia in 20 patients and under spinal anesthesia in 65 patients. In all patients, both femoral arteries were surgically removed, and stent grafts were placed after a bolus of heparin was administered at $100 \mathrm{IJ} / \mathrm{kg}$.

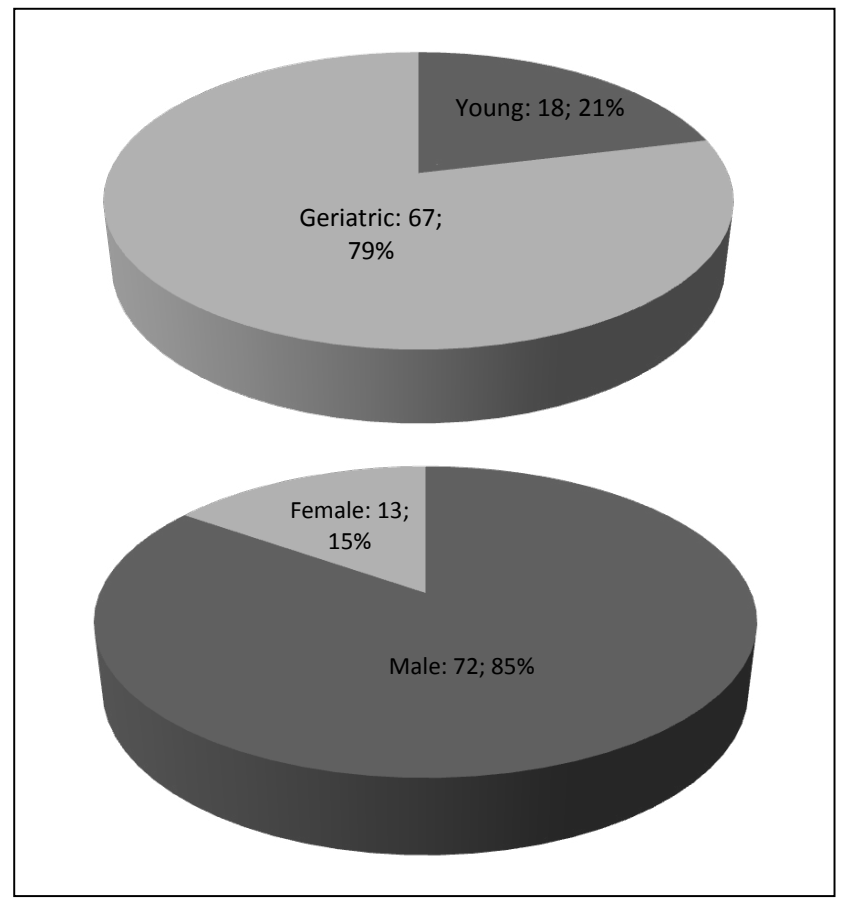

Fig. 1 - Descriptive Properties.

Table 1. Patients' descriptive characteristics.

\begin{tabular}{|c|c|c|c|}
\hline Characteristic & Group & Frequency (n) & Percent (\%) \\
\hline \multirow{3}{*}{ Age } & Young & 18 & 21.2 \\
\hline & Geriatric & 67 & 78.8 \\
\hline & Total & 85 & 100 \\
\hline \multirow{3}{*}{ Gender } & Male & 72 & 84.7 \\
\hline & Female & 13 & 15.3 \\
\hline & Total & 85 & 100 \\
\hline \multirow{9}{*}{ Chronic disease } & CAD & 45 & 52.9 \\
\hline & CAD+COPD & 20 & 23.5 \\
\hline & CAD+COPD+obesity & 8 & 9.4 \\
\hline & CAD+obesity & 5 & 5.9 \\
\hline & CAD+PAD & 1 & 1.2 \\
\hline & COPD & 4 & 4.7 \\
\hline & Obesity & 1 & 1.2 \\
\hline & CKD+CAD+COPD & 1 & 1.2 \\
\hline & Total & 85 & 100 \\
\hline \multirow{5}{*}{ Result } & Failure & 2 & 2.4 \\
\hline & Exitus & 3 & 3.5 \\
\hline & CKD & 3 & 3.5 \\
\hline & Cure & 77 & 9.6 \\
\hline & Total & 85 & 100 \\
\hline
\end{tabular}

$\mathrm{CAD}=$ coronary artery disease; $\mathrm{CKD}=$ chronic kidney disease; $C O P D=$ chronic obstructive pulmonary disease; $P A D=$ peripheral arterial disease 
Table 2. Patients' averages

\begin{tabular}{l|c|c|c|c|c}
\hline & N & Mean & SD & Min. & Max. \\
\hline Age & 85 & 71.080 & 8.656 & 49.000 & 85.000 \\
\hline Aneurysm diameter & 85 & 71.590 & 12.551 & 56.000 & 121.000 \\
\hline Neck angle & 85 & 64.390 & 18.447 & 20.000 & 110.000 \\
\hline Neck length & 85 & 14.120 & 6.132 & 5.000 & 25.000 \\
\hline Right iliac angle & 85 & 50.590 & 13.875 & 20.000 & 90.000 \\
\hline Left iliac angle & 85 & 50.470 & 14.426 & 20.000 & 95.000 \\
\hline
\end{tabular}

$\mathrm{SD}=$ standard deviation

After the stent graft was placed, control aortography was performed to evaluate graft clearance and possible leakage. The following devices were used in EVAR in this study: Endurent ${ }^{\mathrm{TM}}$ (Medtronic) in 70 patients (82.3\%), Anaconda ${ }^{\mathrm{TM}}$ in six (7\%), Ovation $^{\mathrm{TM}}$ in three (3.5\%), Aorfix ${ }^{\mathrm{TM}}$ in one $(1.1 \%)$, and others in five (5.8\%). The evaluated outcomes included in-hospital mortality, complications, and reintervention. The primary study outcome was technical success; the secondary endpoints were mortality and secondary intervention. Technical success was defined as the successful delivery and application of the endograft without intentionally involving the renal, internal iliac, or visceral arteries.

All patients' data were analyzed, specifically general patients' characteristics and post-EVAR outcomes, from patients' charts and physicians' follow-up notes. The database included age, sex, comorbidity, and anatomical factor data. The comorbidities we observed included hypertension, diabetes mellitus (DM), coronary artery disease (CAD), peripheral arterial disease (PAD), renal dysfunction, chronic obstructive pulmonary disease (COPD), and obesity.

The following parameters were recorded: age of the patients, diameter of the aneurysms, neck angle, neck length, iliac angles, complications, and mortality. Regarding operative data, we recorded the model of stent used in the surgery, whether any concomitant procedures were performed, and whether there were any intra-operative complications. The follow-up data consisted of the incidence of endoleaks, reinterventions, complications, and mortality.

All patients were imaged with computed tomography (CT) scans at discharge as well as three, six, and 12 months after the primary repair; patients were imaged annually thereafter.

\section{Statistical Methods}

The data obtained in the study were analyzed using the Statistical Package for Social Sciences software for Windows, version 22.0 (SPSS, Chicago, IL). The following descriptive statistics were used: number, percentage, mean, and standard deviation. The relationships between group variables were tested by chisquared analysis. Student's t-test was used to compare the quantitative continuous data between the two independent groups. The findings were evaluated at a 95\% confidence interval and 5\% significance level. Statistical significance was set at a $P$-value of $<0.05$.

\section{RESULTS}

The patients' mean age was 71.1 years, with a standard deviation of 8.6 (range: $49-85$ ) years. The young group comprised $21.2 \%$ (18) of the total patients, whereas $78.8 \%$ (67) of the patients were over 65 years old (the geriatric group). The median follow-up time was 36 months (3-60 months). Forty-five patients (52.9\%) had CAD, 20 (23.5\%) had CAD + COPD, eight (9.4\%) had CAD + COPD + obesity, five (5.9\%) had COPD + obesity, one (1.2\%) had COPD + PAD, four (4.7\%) only had COPD, one (1.2\%) had obesity, and one (1.2\%) had kidney failure + CAD + COPD (Table 1). There was no significant association between sex and age $\left(\chi^{2}=0.033\right.$; $P$-value $\left.=0.553\right)$. In the young group, $15(83.3 \%)$ patients were male and three (16.7\%) were female. Fifty-seven (85.1\%) of the geriatric patients were male and 10 (14.9\%) were female. There was no statistically significant association between chronic disease and age $\left(\chi^{2}=8.001 ; P\right.$-value $\left.=0.333\right)$. And there was no statistically significant association between the outcome and age $\left(\chi^{2}=2.373\right.$; $P$-value $\left.=0.499\right)$ (Table 3$)$.

The mean preoperative AAA neck length was $14.120 \mathrm{~mm}$ (range: 5-25 mm). The angulation of the aortic neck varied from $20^{\circ}$ to $110^{\circ}$ and the mean angulation was $64.39^{\circ}$. The differences between the patients' averages, in terms of aneurysm diameter, neck angle, neck length, right iliac angle, and left iliac angle, considering their ages were not statistically significant $(P$-value $=0.360,0.178,0.141,0.561$, and 0.763 , respectively) (Table 4 ).

Three deaths were reported in the geriatric group on the first day, two of which were due to rupture and the third was due to kidney failure two days after the operation. The resulting mortality rate was 3.5\% (3/85). Endoleaks were detected in 25 (29.4\%) patients during the procedure (Figure 2).

It was also reported renal insufficiency in three people, all of them in the geriatric group; and two of these had ruptured kidneys. Technical success was achieved in all cases except one. Sixty-seven geriatric people underwent EVAR, and only one case was converted to OSR because of a failure to pass the iliac vessels with the stent graft; in this patient, OSR was performed successfully.

The mean intensive care unit (ICU) stay was one day (range: 0-2) and the mean in-hospital stay was three days (range: 1-6).

There was no statistically significant difference in survival rates between the different age groups. After three years, all patients were alive, except those three that died within two days of the operation. 
Table 3. Distribution by age.

\begin{tabular}{|c|c|c|c|c|c|c|}
\hline & & \multicolumn{2}{|c|}{ Young } & \multicolumn{2}{|c|}{ Geriatric } & \multirow{2}{*}{$P$} \\
\hline & & $\mathbf{n}$ & $\%$ & $\mathbf{n}$ & $\%$ & \\
\hline \multirow{2}{*}{ Gender } & Male & 15 & 83.3 & 57 & 85.1 & \multirow{2}{*}{$\begin{aligned} \chi^{2} & =0.033 \\
P & =0.553\end{aligned}$} \\
\hline & Female & 3 & 16.7 & 10 & 14.9 & \\
\hline \multirow{8}{*}{ Chronic disease } & CAD & 8 & 44.4 & 37 & 55.2 & \multirow{8}{*}{$\begin{aligned} \chi^{2} & =8.001 \\
P & =0.333\end{aligned}$} \\
\hline & CAD+COPD & 4 & 22.2 & 16 & 23.9 & \\
\hline & CAD+COPD +obesıty & 3 & 16.7 & 5 & 7.5 & \\
\hline & CAD+obesıty & 3 & 16.7 & 2 & 3 & \\
\hline & CAD+PAD & 0 & - & 1 & 1.5 & \\
\hline & COPD & 0 & - & 4 & 6 & \\
\hline & Obesity & 0 & - & 1 & 1.5 & \\
\hline & CKD+CAD+COPD & 0 & - & 1 & 1.5 & \\
\hline \multirow{4}{*}{ Result } & Failure & 0 & - & 2 & 3 & \multirow{4}{*}{$\begin{array}{l}\chi^{2}=2.73 \\
P=0.499\end{array}$} \\
\hline & Exitus & 0 & - & 3 & 4.5 & \\
\hline & CKD & 0 & - & 3 & 4.5 & \\
\hline & Cure & 18 & 100 & 59 & 88.1 & \\
\hline
\end{tabular}

$\mathrm{CAD}=$ coronary artery disease; $\mathrm{CKD}=$ chronic kidney disease; $\mathrm{COPD}=$ chronic obstructive pulmonary disease; $\mathrm{PAD}=$ peripherial arterial disease

Table 4. Patients' averages by age.

\begin{tabular}{|c|c|c|c|c|c|c|}
\hline \multirow[t]{2}{*}{ Characteristic } & \multicolumn{2}{|c|}{ Young $(n=18)$} & \multicolumn{2}{|c|}{ Geriatric $(n=67)$} & \multirow{2}{*}{$t$} & \multirow{2}{*}{$P$} \\
\hline & Mean & SD & Mean & SD & & \\
\hline Aneurysm diameter & 69.170 & 9.167 & 72.240 & 13.297 & -0.921 & 0.360 \\
\hline Neck angle & 69.610 & 14.884 & 62.990 & 19.147 & 1.360 & 0.178 \\
\hline Neck length & 12.220 & 4.918 & 14.630 & 6.355 & -1.488 & 0.141 \\
\hline Right iliac angle & 48.890 & 12.551 & 51.040 & 14.263 & -0.583 & 0.561 \\
\hline Left iliac angle & 51.390 & 10.955 & 50.220 & 15.286 & 0.303 & 0.763 \\
\hline
\end{tabular}

$\mathrm{SD}=$ standard deviation

Six $(7.05 \%)$ patients underwent renal stent implantation during the same procedure. Five patients were treated with iliac balloon stents (5.8\%). The secondary intervention rate was 7\% (six patients); in the 36-month follow-up, reintervention was performed in six patients. The left iliac graft was extended in two patients, aortic extension was applied to two patients, one patient underwent aneurysmography with OSR, and one patient underwent a femorofemoral bypass. One of these patients was in the young group; all the others (five patients) were in the geriatric group.

Bi-iliac grafts were used in 82 cases. Only three patients were treated with aorto-uni-iliac grafts and one of them underwent a femorofemoral extra-anatomical bypass.

There was no association between age and aneurysm morphology, but more endoleaks, reinterventions, and complications were observed in patients over 65 years old, though these differences were not statistically significant.

\section{DISCUSSION}

AAA is more commonly seen in the elderly than in the young, and it mostly affects men. The aim of elective repair is to prevent rupture, which causes mortality. EVAR has been widely used since it was first reported in the 1990s, by Paradi ${ }^{[4]}$. EVAR was first used for ruptured AAAs by Yusuf et al. ${ }^{[5]}$, in 1994.

Once EVAR was established, it was recommended for elderly and high-risk patients. EVAR's promising results made it attractive for treating young people, low-risk patients, and patients with anatomical risks.

Albuquerque et al. ${ }^{[6]}$ reported, on average, an $84 \%$ increase in the use of EVAR between 2005 and 2008, whereas Schwarze et al. ${ }^{[7]}$ 


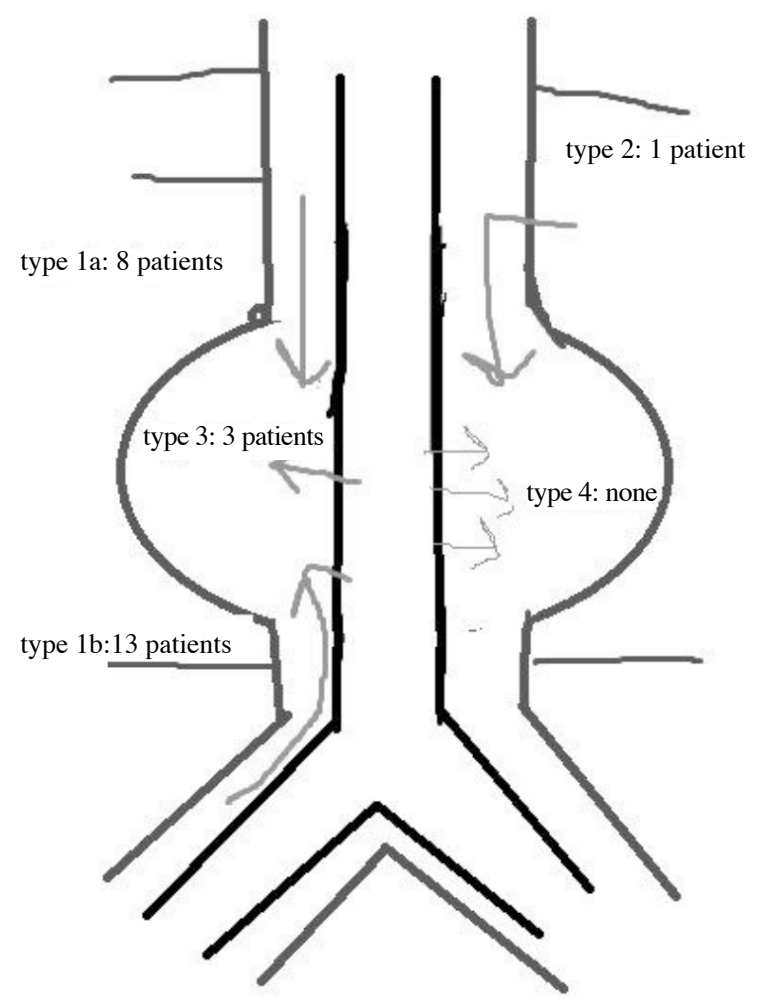

Fig. 2 - Endoleak types.

reported a 162\% increase in EVAR for patients over 85 years old. EVAR is less invasive and better tolerated than conventional OSR.

Several randomized controlled trials and large prospective registries reported that in anatomically suitable patients for nonruptured and ruptured AAAs, EVAR had significant benefits over OSR, regarding early mortality, and had similar medium-term results ${ }^{[8,9]}$. The benefits of EVAR are reduced blood loss, shorter in-hospital stays, and decreased operative mortality compared to open aneurysm repair ${ }^{[10,11]}$.

EVAR needs more secondary interventions, making it necessary to follow up with patients. But EVAR can be performed safely and effectively in both young and geriatric patients. While age is correlated with an increased risk of cardiovascular disease, hypercholesterolemia, and cerebrovascular disease ${ }^{[12]}$, we saw no differences in the rates of these diseases between the young and geriatric groups in our study.

Machado et al. ${ }^{[13]}$ reported that age $\geq 80$ years influences the survival curve in only OSR group. But in a study by Schermerhorn et al. ${ }^{[14]}$, when the age increased, the survival rate decreased, even in the EVAR group. A meta-analysis revealed that octogenarians have higher perioperative and mid-term mortality rates than younger patients ${ }^{[15]}$; however, we found no significant difference in survival rates between the young and geriatric groups.

The main post-EVAR complications are endoleak and reintervention ${ }^{[16]}$. The majority of endoleaks can be treated with endovascular techniques, though sometimes open surgical interventions are required ${ }^{[17]}$, as seen in 25 patients in our study. The majority of Type la endoleaks resolved spontaneously without the need for a secondary procedure in the controls. The secondary interventions are generally used to resolve endograft migration and Type I and III endoleaks. Saadi et al. ${ }^{[18]}$ reported that the survival rate free from reinterventions is 96\% after 27 months without operative or postoperative deaths. In our study, six (7\%) patients (one young, five geriatric) underwent secondary intervention procedures (five endovascular, one OSR); in contrast, the literature states that secondary interventions occur in $7-13.3 \%$ of patients ${ }^{[13,19]}$.

The life expectancy of AAA patients is the major factor that determines which therapy should be pursued. EVAR is a safe and effective treatment for AAA with low (1-2\%) perioperative mortality ${ }^{[20]}$.

Pol et al. ${ }^{[21]}$ reported that higher mortality and morbidity rates are seen in elderly patients than in younger ones, with aortic stent grafts.

Altaf et al. ${ }^{[22]}$ reported a $40 \%$ mortality rate among youths over a six-year period and reported that most of these deaths were unrelated to the aneurysm.

Mani et al. ${ }^{[23]}$ reported a five-year survival rate of $69 \%$ and a 10-year survival rate of $39.3 \%$ after elective EVAR and reported no significant difference in survival between ages. Machado et al. ${ }^{[24]}$ reported a global post-EVAR mortality rate of 1.2\%. They reported only two mortalities in the over-80-years-old group and zero mortality in both groups that were younger than 80-years-old. In our study, there was no mortality in the young group and three patients (3.5\%) in the geriatric group died from causes related to EVAR, suggesting that age alone can explain the higher mortality rates reported in the literature. There were no statistical differences in the mortality and reinterventions rates between the groups.

\section{Study Limitations}

The major limitations of this study include the small numbers of patients and the retrospective nature of the analysis. Also, the different types of grafts could affect the results.

\section{CONCLUSION}

Our single-center study shows that it is safe and feasible to repair AAAs via EVAR. Since there were no statistically significant differences in the mortality and reintervention rates between the age groups, EVAR can be used safely in patients of all ages. The advantages of EVAR include that it is a less invasive operative procedure and it generally results in shorter ICU and in-hospital stays than OSR. Reinterventions are the Achilles' heel of this procedure; however, technological improvements should reduce these complications in the near future.

\section{ACKNOWLEDGEMENT}

We acknowledge the medical writing assistance provided by American Manuscript Editors (www.americanmanuscripteditors. com).

\section{No financial support. \\ No conflict of interest.}




\section{Authors' roles \& responsibilities}

MY Analysis and interpretation of data; drafting the paper; final approval of the version to be published

OT Conception and design of the work; acquisition of data; revising the work; final approval of the version to be published

\section{REFERENCES}

1. Sanfelippo PM. Abdominal aortic aneurysm-2003: what we know, what we don't know - a review. Int J Angiol. 2003;12(3):145-52. doi:10.1007/ s00547-003-1040-0.

2. Greenhalgh RM, Brown LC, Powell JT, Thompson SG, Epstein D, Sculpher MJ. Endovascular versus open repair of abdominal aortic aneurysm. N Engl J Med. 2010;362(20):1863-71. doi:10.1056/NEJMoa0909305.

3. Khashram M, Williman JA, Hider PN, Jones GT, Roake JA. Systematic review and meta-analysis of factors influencing survival following abdominal aortic aneurysm repair. Eur J Vasc Endovasc Surg. 2016;51(2):203-15. doi:10.1016/j.ejvs.2015.09.007.

4. Parodi JC, Palmaz JC, Barone HD. Transfemoral intraluminal graft implantation for abdominal aortic aneurysms. Ann Vasc Surg. 1991;5(6):491-9. doi:10.1007/BF02015271.

5. Yusuf SW, Whitaker SC, Chuter TA, Wenham PW, Hopkinson BR. Emergency endovascular repair of leaking aortic aneurysm. Lancet. 1994;344(8937):1645.

6. Albuquerque Jr FC, Tonnessen BH, Noll Jr RE, Cires G, Kim JK, Sternbergh 3rd WC. Paradigm shifts in the treatment of abdominal aortic aneurysm: trends in 721 patients between 1996 and 2008. J Vasc Surg. 2010;51(6):1348-52. doi:10.1016/j.jvs.2010.01.078.

7. Schwarze ML, Shen Y, Hemmerich J, Dale W. Age-related trends in utilization and outcome of open and endovascular repair for abdominal aortic aneurysm in the United States, 2001-2006. J Vasc Surg. 2009;50(4):722-9. doi:10.1016/j.jvs.2009.05.010.

8. Geisbüsch P, Katzen BT, Tsoukas Al, Arango D, Pena CS, Benenati JF. Endovascular repair of infrarenal aortic aneurysms in octogenarians and nonagenarians. J Vasc Surg. 2011;54(6):1605-13. doi:10.1016/j. jvs.2011.06.096.

9. De Bruin JL, Baas AF, Buth J, Prinssen M, Verhoeven EL, Cuypers PW, et al. Long-term outcome of open or endovascular repair of abdominal aortic aneurysm. N Engl J Med. 2010;362(20):1881-9. doi:10.1056/ NEJMoa0909499.

10. Chahwan S, Comerota AJ, Pigott JP, Scheuermann BW, Burrow J, Wojnarowski D. Elective treatment of abdominal aortic aneurysm with endovascular or open repair: the first decade. JVasc Surg. 2007;45(2):25862. doi:10.1016/j.jvs.2006.09.046.
11. Greenhalgh RM, Brown LC, Kwong GP, Powell JT, Thompson SG. Comparison of endovascular aneurysm repair wiyh open repair in patients with abdominal aortic aneurysm (EVAR trial 1), 30-day operative mortality results: randomised controlled trial. Lancet. 2004;364(9437):843-8. doi:10.1016/S0140-6736(04)16979-1.

12. Png C, Tadros R, Faries P, Torres M, Kim S, Lookstein R, et al. The effect of age on post-EVAR outcomes. Ann Vasc Surg. 2016;35:156-62. doi:10.1016/j.avsg.2016.01.022.

13. Machado R, Antunes IL, Oliveira P, Pereira C, de Almeida R. Institutional Impact of EVAR's Incorporation in the Treatment of Abdominal Aortic Aneurysm: a 12 Years' Experience Analysis. Braz J Cardiovasc Surg. 2016;31(2):98-105. doi:10.5935/1678-9741.20160028.

14. Schermerhorn ML, O'Malley AJ, Jhaveri A, Cotterill P, Pomposelli F, Landon $B E$. Endovascular vs. open repair of abdominal aortic aneurysms in the medicare population. N Engl J Med. 2008;358(5):464-74. doi:10.1056/ NEJMoa0707348.

15. Han Y, Zhang S, Zhang J, Ji C, Eckstein HH. Outcomes of endovascular abdominal aortic aneurysm repair in octogenarians: meta-analysis and systemic review. Eur J Vasc Endovasc Surg. 2017;54(4):454-63. doi:10.1016/j.ejvs.2017.06.027.

16. Chang RW, Goodney P, Tucker LY, Okuhn S, Hua H, Rhoades A, et al. Tenyear results of endovascular abdominal aortic aneurysm repair from a large multicenter registry. J Vasc Surg. 2013;58(2):324-32. doi:10.1016/j. jvs.2013.01.051.

17. Schlösser FJ, Muhs BE. Endoleaks after endovascular abdominal aortic aneurysm repair: what one needs to know. Curr Opin Cardiol. 2012;27(6):598-603. doi:10.1097/HCO.0b013e3283582fc0.

18. Saadi EK, Gastaldo F, Dussin LH, Zago AJ, Barbosa G, Moura L. Endovascular treatment of abdominal aortic aneurysms: initial experience and short and mid-term results. Braz J Cardiovasc Surg. 2006;21(2): 211-6. doi:10.1590/S0102-76382006000200016.

19. Chang D, Parina R, Wilson S. Survival after endovascular vs open aortic aneurysm repairs. JAMA Surg. 2015;150(12):1160-6. doi:10.1001/ jamasurg.2015.2644.

20. Propper BW, Abularrage CJ. Long-term safety and efficacy of endovascular abdominal aortic aneurysm repair. Vasc Health Risk Manag. 2013;9:135-41. doi:10.2147/NHRM.S32250.

21. Pol RA, Zeebregts CJ, Van Sterkenburg SMM, Ferreira LM, Goktay Y, Reijnen MM. Outcome and quality of life after endovascular abdominal aortic aneurysm repair in octogenarians. JVasc Surg. 2014;60(2):308-17. doi:10.1016/j.jvs.2014.02.009.

22. Altaf N, Abisi S, Yong Y, Saunders JH, Braithwaite BD, MacSweeney ST. Mid-term results of endovascular aortic aneurysm repair in the young. Eur J Vasc Endovasc Surg:46(3):315-9. doi:10.1016/j.ejvs.2013.04.027.

23. Mani K, Björck M, Lundkvist J, Wanhainen A. Improved long-term survival after abdominal aortic aneurysm repair. Circulation. 2009;120(3):201-11. doi:10.1161/CIRCULATIONAHA.108.832774.

24. Machado R, Teixeira G, Oliveira P, Loureiro L, Pereira C, Almeida R. Is age a determinant factor in EVAR as a predictor of outcomes or in the selection procedure? Our experience. Braz J Cardiovasc Surg. 2016;31(2):132-9. doi:10.5935/1678-9741.20160037. 